\title{
PDGFR Protein Overexpression
}

National Cancer Institute

\section{Source}

National Cancer Institute. PDGFR Protein Overexpression. NCI Thesaurus. Code C148405.

A molecular abnormality indicating the presence of an abnormally high level of a plateletderived growth factor receptor family protein. 